\title{
Synapse Formation in the Absence of Cell Bodies Requires Protein Synthesis
}

\author{
Samuel Schacher and Fang Wu \\ Center for Neurobiology and Behavior, Columbia University College of Physicians and Surgeons and New York State \\ Psychiatric Institute, New York, New York 10032
}

\begin{abstract}
Protein synthesis at distal synaptic sites is thought to play a critical role in long-term synaptic plasticity at preexisting connections. We tested whether protein synthesis in distal neuritic processes contributes to the formation of new synaptic connections by Aplysia neurons regenerating in cell culture after removing their cell bodies. Removal of either the sensory neuron (SN) or motor cell $L 7$ cell body did not affect the formation of synaptic connections during the next 48-72 hr period. Increases in synaptic efficacy after removal of the SN cell body was accompanied by neurite growth and an increase in the number of SN varicosities contacting L7. The increases in synaptic efficacy and the number of $\mathrm{SN}$ varicosities were
\end{abstract}

Synapses remain functional long after removal of the cell bodies of either presynaptic or postsynaptic neurons (Bittner, 1991; Kang and Schuman, 1996). The long-term maintenance of synaptic efficacy and the capacity to express activity-dependent changes even in the absence of neuronal cell bodies suggest that local metabolic activity can support synapse function and plasticity. Metabolic support may be provided by transfer of critical macromolecules synthesized in neighboring cells that retain their cell bodies (glia or other neurons) or from local protein synthesis in the distal processes of the injured cells via translation of mRNAs transported from cell bodies.

Is local translation of proteins encoded by mRNAs transported to distal sites of a neuron necessary for the growth and development of new synaptic connections? Inhibition of protein synthesis at specific times at or near distal synaptic sites can disrupt longterm synaptic plasticity (Kang and Schuman, 1996; Martin et al., 1997; Sherff and Carew, 1999; Huber et al., 2000). Several mRNAs transported to distal sites encode a variety of proteins that might contribute to long-term synaptic plasticity: calcium/ calmodulin-dependent protein kinase II, cytoskeletal and their binding proteins, and transmitter receptors (Crino and Eberwine, 1996; Steward and Schuman, 2001). The local translation of some of these mRNAs appear to contribute toward cellular changes associated with long-term plasticity at preexisting synaptic inter-

Received Sept. 17, 2001; revised Nov. 15, 2001; accepted Dec. 18, 2001.

This research was supported by National Science Foundation Grant IBN-9808938 and National Institutes of Health Grant MH-60387. Animals were provided by the National Center for Research Resources for Aplysia at the University of Miami supported by National Institutes of Health Grant RR 10294. We thank Rachel Yarmolinsky and Eve Vagg for assistance in preparing the figures and Drs. Koester, Kupfermann, and Schwartz for comments on this manuscript.

Correspondence should be addressed to Samuel Schacher, Center for Neurobiology and Behavior, Columbia University College of Physicians and Surgeons, New York State Psychiatric Institute, 1051 Riverside Drive, New York, NY 10032. E-mail:sms2@columbia.edu.

Copyright (C) 2002 Society for Neuroscience $0270-6474 / 02 / 221831-09 \$ 15.00 / 0$ blocked by anisomycin, a protein synthesis inhibitor. The initial formation of synaptic connections was not affected by the absence of the $L 7$ cell body. In the absence of cell bodies from both presynaptic and postsynaptic cells, synaptic efficacy increased for $48 \mathrm{hr}$ and was blocked reversibly by anisomycin. These results support the idea that distal neuritic processes contain stable mRNAs and the macromolecular machinery for protein synthesis that are required for the formation of new synaptic connections.

Key words: synapse formation; axon growth; local protein synthesis; neuritic mRNA; Aplysia; cell culture

actions (Steward et al., 1998; Wu et al., 1998; Casadio et al., 1999; Sheetz et al., 2000). It is unclear, however, whether the local synthesis of these macromolecules is both necessary and sufficient to allow de novo synapses to form.

Protein synthesis at or near distal synaptic sites contributes to the expression of some forms of long-term facilitation at preexisting sensorimotor synapses in Aplysia (Martin et al., 1997; Casadio et al., 1999; Sherff and Carew, 1999). Local protein synthesis may contribute to plasticity associated with long-lasting morphological changes in the arbor of the presynaptic sensory neuron (Martin et al., 1997; Casadio et al., 1999). Is local protein synthesis required during the initial growth, formation, and maturation of synapses between a sensory neuron (SN) and motor neuron L7? In dissociated cell culture, it is possible to follow the formation and maturation of new synapses by Aplysia SNs (Glanzman et al., 1989; Bank and Schacher, 1992; Zhu et al., 1994). New synapses form via growth cone extension and establishment of varicosities at sites with high density of cell surface adhesion molecules (Zhu et al., 1994; Hatada et al., 1999, 2000). Synapse formation and maturation are accompanied by the induction and local clustering of functional NMDA-like receptors and the subsequent addition of functional AMPA-like receptors at postsynaptic sites near SN varicosities (Conrad et al., 1999). In addition, interaction with an appropriate synaptic partner and neuromodulators regulate the local accumulation of SN-specific mRNA transported to distal sites (Schacher et al., 1999; Sun et al., 2001). Together, these findings suggest that local protein synthesis at sites of interaction between $\mathrm{SN}$ and appropriate targets might contribute to the formation of synaptic connections.

To test whether local synthesis contributes to de novo synapse formation, we followed changes in synaptic efficacy and structure after removing the cell body of the presynaptic SN, the postsynaptic L7, or both. We found that formation of synaptic connections was not affected and continued during a 48-72 hr period. 
However, formation of new synaptic connections was blocked reversibly by protein synthesis inhibition. These results suggest that local translation of stable mRNAs transported to distal sites is required for the formation of new synaptic connections.

\section{MATERIALS AND METHODS}

Cell culture and electrophysiology. SNs were isolated from pleural ganglia dissected from adult animals (80-100 gm), and motor cell L7 was isolated from juvenile (1-3 gm) abdominal ganglia and maintained in culture for up to $4 \mathrm{~d}$ as described previously (Rayport and Schacher, 1986; Schacher et al., 1999). Cocultures consisted of one SN with one L7 (SN-L7).

Cell bodies were removed as described previously (Schacher et al., 1999, their Fig. 2). The SN cell body was dissected $24-48 \mathrm{hr}$ after plating, and the strength of connections between the cells was reexamined over the next $48 \mathrm{hr}$. Removing the SN cell body earlier often resulted in the detachment of the remaining axon from the substrate and subsequent degeneration. The cell body of L7 was removed 15-18 hr after plating. An SN was then added to the cultures 2-3 hr after dissecting the L7 cell body. By that time, a stable stump forms at the dissection site of the axon of L7. Cultures were reexamined during the next 24-72 hr.

Standard electrophysiological techniques were used to record the amplitude of the EPSP evoked in L7 before and after cell body removal. In some cultures, the protein synthesis inhibitor anisomycin $(20 \mu \mathrm{M})$ was added to the culture medium and washed out $24 \mathrm{hr}$ later. Motor cell L7 (cell body or axon stump) was impaled with a microelectrode (resistance of $15-20 \mathrm{M} \Omega$ ) containing $2.0 \mathrm{M} \mathrm{K}$-acetate, $0.5 \mathrm{M} \mathrm{KCl}$, and $10 \mathrm{~mm}$ K-HEPES, pH 7.6, and held at $-85 \mathrm{mV}$. Each SN was stimulated with a brief $(0.3 \mathrm{msec})$ depolarizing pulse to evoke an action potential using an extracellular electrode placed near the cell body or axon stump of the SN. Control and experimental cultures were matched so that the baseline of EPSP amplitude was comparable before cutting the axons. After $2 \mathrm{~d}$ in culture, weak synaptic connections (EPSP $<8 \mathrm{mV}$ ) and large connections $($ EPSP $>30 \mathrm{mV}$ ) show smaller changes over time.

Dye injection and imaging of structural changes. The fluorescent dye 5(6)-carboxyfluorescein (6\% in $0.44 \mathrm{M} \mathrm{KOH,} \mathrm{pH} \mathrm{7.0;} \mathrm{Molecular} \mathrm{Probes,}$ Eugene, OR) was injected into SNs with 0.3-0.4 nA hyperpolarizing current pulses (500 $\mathrm{msec}$ at $1 \mathrm{~Hz}$ ) for 5-6 min (Glanzman et al., 1989). Nomarski or phase contrast and fluorescent images of the same view areas along the axons of L7 were taken to map out the location of SN varicosities and neurites at each time point. Images were taken with a Nikon (Tokyo, Japan) Diaphot microscope attached to an SIT (Dage 68; Dage-MTI, Michigan City, IN) video camera, processed by a Dell 310 computer with a personal computer Vision Plus frame grabber, and subsequently stored on compact disks. Alignment of the live view area at the second time point with the initial recorded image was aided by the computer, with fine adjustments made with the stage controls, and by manual rotation of the culture dish. Illumination used for obtaining fluorescent images was kept as low as possible to prevent photodamage. To minimize differences in imaged structures that might arise as a result of differences in the extent of dye filling, light intensities used at the second time point were adjusted to match the intensity of the stored images taken before treatment.

Quantification of structural changes. Counts of the number of varicosities were obtained from fluorescent images of SN neurites contacting the proximal $350-400 \mu \mathrm{m}$ of the axon of L7. Previous studies had indicated that this portion of the axon of L7 is the most favorable substrate for growth of SN neurites that form varicosities with transmitter release sites (Glanzman et al., 1989; Schacher et al., 1990). SN varicosities can be found at any position along this proximal portion of the axon of L7 (Bank and Schacher, 1992). Because the axon of L7 is a relatively thick structure, it often required as many as four different focal planes to image all of the labeled neurites and varicosities in a given view area. To minimize slight differences in focus that could obscure differences in varicosity number, we used computer-assisted superimposition of the various focal planes onto a single two-dimensional image. The matched fluorescent images of each focal plane along with the superimpositions for both time points were compared, and the total number of varicosities was counted. Structures that were slightly elongated spheres greater or equal to $1.5 \mu \mathrm{m}$ connected by narrow neuritic necks were counted as varicosities (Bailey and Chen, 1983, 1988). Counts of varicosities were performed blind; the individual did not know the amplitude of the EPSPs before or after treatment or the nature of the treatment. Only net change in varicosity number (not changes in varicosity shape) was used to measure structural changes evoked with treatments.

Data analysis. Average EPSP amplitudes and varicosity numbers per treatment are given as means \pm SEM. Effects of treatment were calculated using ANOVAs, and the significance of differences between treatment groups and control was measured with a multicomparison test (Dunnett's).

\section{RESULTS}

\section{Changes in synaptic efficacy and axon growth in the absence of $\mathrm{SN}$ cell body require new protein synthesis}

New synapses form between SN and L7 by $15 \mathrm{hr}$ after plating and continue to form over the next $4 \mathrm{~d}$ (Z hu et al., 1994). The increase in EPSP amplitude (synaptic efficacy) during the first $4 \mathrm{~d}$ in culture is accompanied by the growth of new SN neurites from the axon stump and the formation of new SN varicosities (Glanzman et al., 1989; Bank and Schacher, 1992; Zhu et al., 1994). SN varicosities contacting the major processes of $\mathrm{L} 7$ contain release sites (one to three active zones per varicosity). $\mathrm{SN}$ varicosities do not contain release sites when contacting the substrate or target neuron L11, which fail to respond to action potential activity in the SN (Glanzman et al., 1989). Neurite outgrowth from Aplysia neurons in culture does not require the presence of cell bodies (Benbassat and Spira, 1994). We first examined whether new synaptic contacts between SN and target cell L7 continues to form when the SN cell body is removed.

Synaptic efficacy increased after removing the SN cell body (Fig. 1). After measuring EPSP amplitude in 2-d-old cultures, the SN cell body was removed (Fig. $1 A, B$ ), and EPSP amplitudes were reexamined twice during the next $24 \mathrm{hr}$. Neurites grew from the new SN axon stump formed after cell body dissection in all cases (Fig. 1B, arrow). Cutting the SN axon produces the firing of action potentials (10-20) lasting several seconds that evoke EPSPs in the target cell (Fig. 1C). Control and experimental cultures were matched so that the baseline of EPSP amplitude was comparable before cutting the axons $(16.3 \pm 3.3 \mathrm{mV}$ for the control group and 17.2 $\pm 2.5 \mathrm{mV}$ for the cut axon group). EPSP amplitudes increased for both groups at both 4 and $24 \mathrm{hr}(21.2 \pm$ 3.6 and $30.7 \pm 5.3 \mathrm{mV}$ for the control group compared with $22.0 \pm 3.4$ and $33.8 \pm 5.6 \mathrm{mV}$ for the cut axon group) (Fig. $1 D, E$ ). An ANOVA indicated no significant difference in the changes in EPSP amplitude ( $n=6$ cultures for each group; $F=0.711 ; p>$ $0.5)$. Cutting the $\mathrm{SN}$ axon and removing the $\mathrm{SN}$ cell body does not affect the typical increases in synaptic efficacy that is observed in control cultures.

Changes in the efficacy of SN-L7 synapses is accompanied by an increase in the number of SN varicosities contacting the major processes of L7 (Glanzman et al., 1989; Bank and Schacher, 1992; Zhu et al., 1994). New varicosities contacting the major processes of L7 contain active sites (Schacher et al., 1990; Hatada et al., 1999). We next examined whether new $\mathrm{SN}$ varicosities can form after removal of the $\mathrm{SN}$ cell body and whether the changes in synaptic efficacy and the number of new SN varicosities require new protein synthesis (Fig. 2).

The increase in synaptic efficacy $24 \mathrm{hr}$ after removal of the SN cell body was accompanied by an increase in SN varicosities. After $2 \mathrm{~d}$ in culture, EPSP amplitude before removing SN cell body was $17.8 \pm 4.3 \mathrm{mV}$ for the control group ( $n=6$ cultures) and $21.4 \pm 4.4 \mathrm{mV}$ for the anisomycin-treated group ( $n=6$ cultures). The average EPSP amplitude in the control group increased significantly to $31.0 \pm 4.0 \mathrm{mV}$ after $24 \mathrm{hr}$ compared with the initial EPSP $(p<0.05)$. The average EPSP amplitude in the anisomycin-treated group was $20.8 \pm 3.6 \mathrm{mV}$ and was not signif- 
A
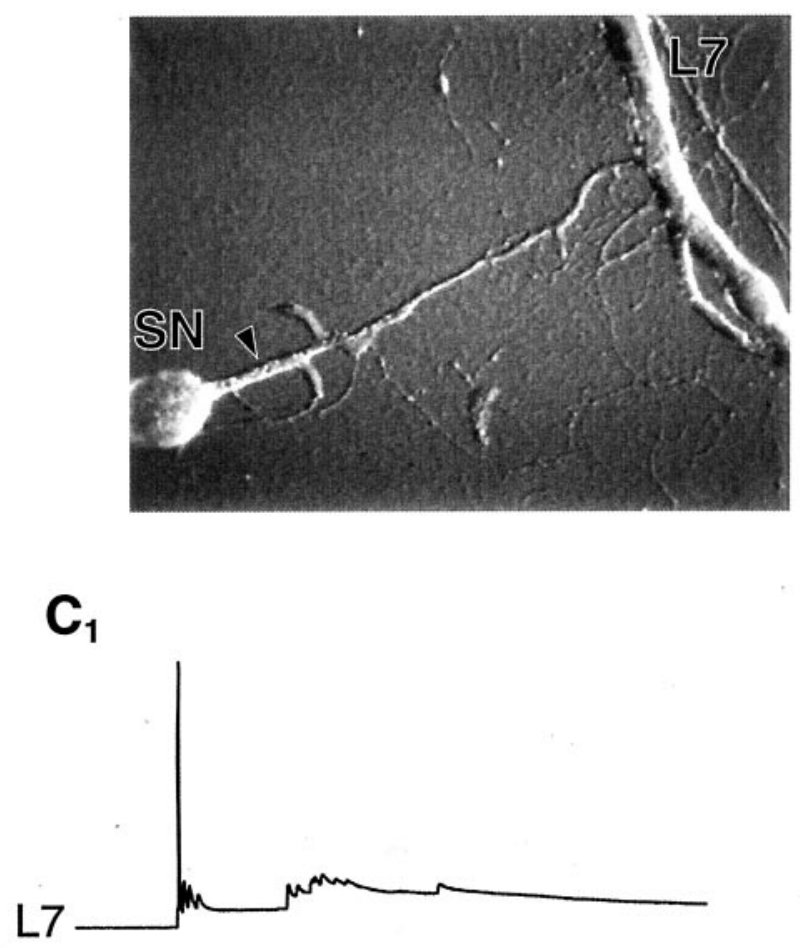

D
B

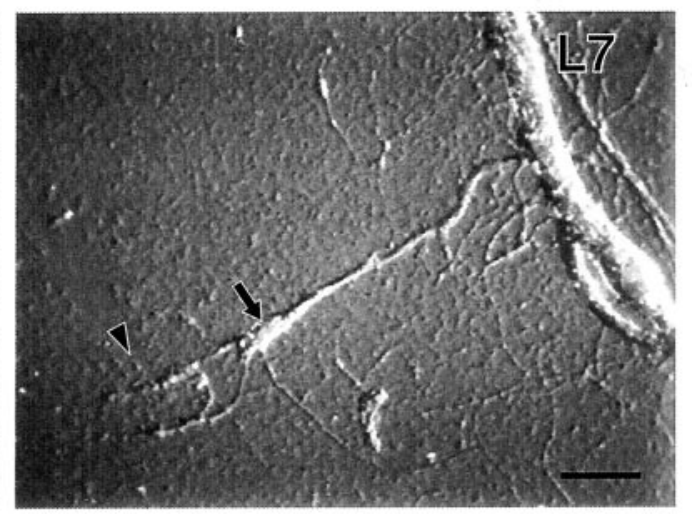

$\mathbf{C}_{2}$

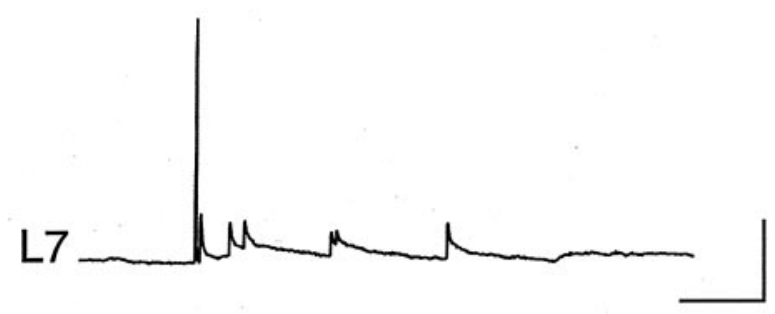

$\mathbf{E}$
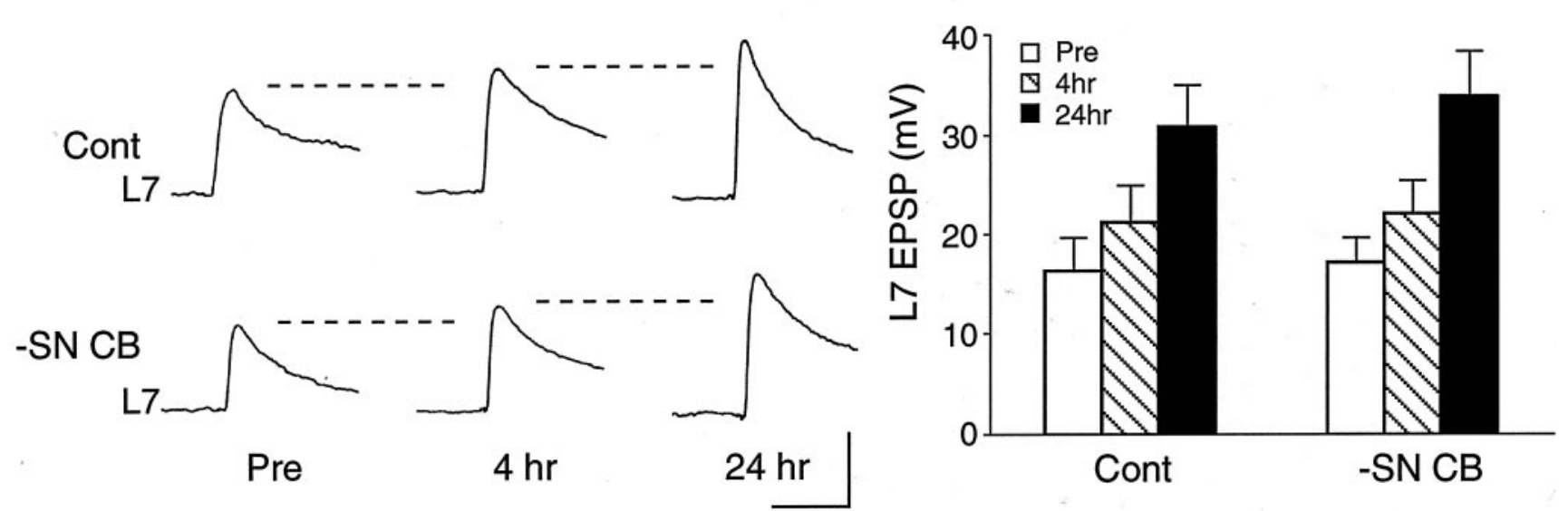

Figure 1. Increases in synaptic efficacy $24 \mathrm{hr}$ after removal of the $\mathrm{SN}$ cell body. $A, B$, Photomicrographs of an $\mathrm{SN}-\mathrm{L} 7$ culture before $(A)$ and 24 hr after $(B)$ cutting the SN axon at the arrowhead. A portion of the L7 axon can be seen in the top right corner. An extracellular electrode place near the new axon stump (arrow in $B$ ) is used to evoke EPSPs in L7. Dye-filled electrodes inserted at the SN axon stump are used for imaging SN neurites contacting L7 (Fig. 2). Scale bar, $50 \mu \mathrm{m}$. $C$, Examples of two traces before and after cutting the SN axon while recording intracellularly from L7. An initial high-frequency burst of EPSPs is followed by low-frequency bursts. Note the rapid decline in EPSP amplitude typical of homosynaptic depression. Calibration: $10 \mathrm{mV}, 0.5 \mathrm{sec}$. D, Examples of EPSPs evoked in L7 before (Pre) and after ( $4 \mathrm{hr}$ and $24 \mathrm{hr})$ control treatment (CONT) and cutting the SN axon and removing the SN cell body $(-S N C B)$. EPSP amplitudes increase for both groups. Calibration: $15 \mathrm{mV}, 25 \mathrm{msec}$. $E$, Summary of the mean \pm SEM of the EPSP amplitudes recorded before (Pre) and at two time points after control (CONT) and experimental $(-S N C B)$ treatment. There was no significant difference in the increases in EPSP amplitude over time (see Results).

icantly different from the initial EPSP amplitude. In the same cultures, we examined the structure of the $\mathrm{SN}$ arbors contacting the major processes of $\mathrm{L} 7$ (Fig. $2 A, D$ ) after injection of carboxyfluoroscein into the SN cell body before removing the $\mathrm{SN}$ cell body and $24 \mathrm{hr}$ later after injection of the same dye into the stump of the SN axon. The increase in EPSP amplitude in the control group was accompanied by an $\sim 40 \%$ increase in the number of new varicosities: $12.6 \pm 2.5$ varicosities $(p<0.05)$ (Fig. $2 B, C$ ) The cultures treated with anisomycin failed to show a significant change in the number of $\mathrm{SN}$ varicosities: $-0.8 \pm 1.1$ varicosities (Fig. 2E,F). Thus, the increases in EPSP amplitude and the number of SN varicosities that develop in the absence of the SN cell body require new protein synthesis.

The effect of treatment with anisomycin on the changes in 

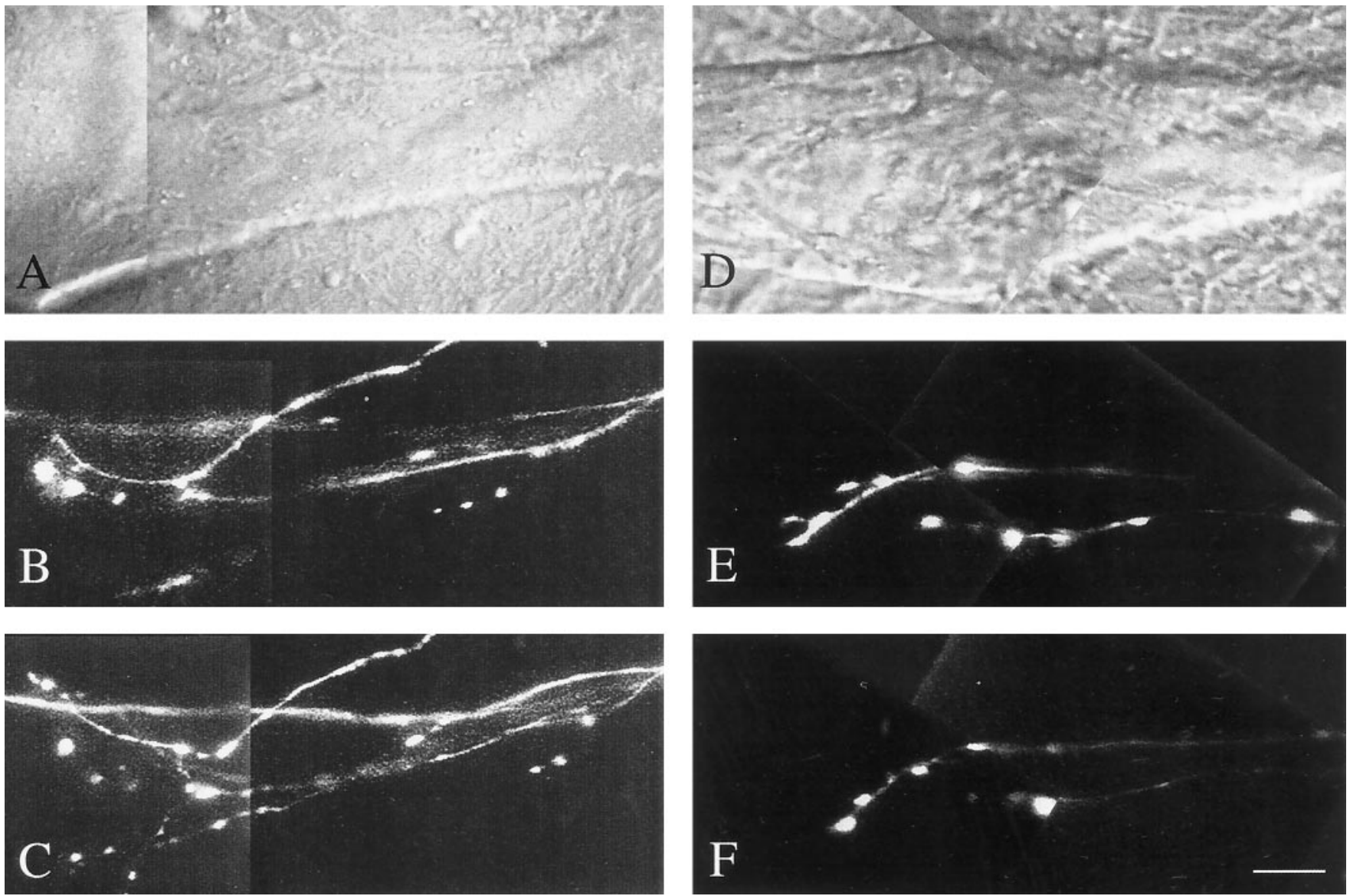

Figure 2. Protein synthesis-dependent outgrowth and varicosity formation in the absence of the SN cell body. $A, D$, Nomarski optics photomicrographs of a portion of the major axons of $\mathrm{L} 7$ in control $(A)$ and anisomycin-treated $(D)$ cultures that are viewed in the epifluorescent images. SN neurites extend and varicosities form along the major processes of L7. $B, C$, Epifluorescent montage of SN neurites and varicosities interacting with the same region of L7 processes before $(B)$ and $24 \mathrm{hr}$ after $(C)$ removal of the SN cell body. Dye was injected into the SN cell body in $A$ and into the SN axon stump in $B$. Note the extension of three neurites and the formation of several new varicosities on the major process of L7. $E, F$, New growth and varicosity formation are blocked by anisomycin. Fluorescent images of SN neurites interacting with the same region of L7 processes before ( $E$ ) and $24 \mathrm{hr}$ after $(F)$ removal of the SN cell body. Anisomycin was added to the culture 30-60 min after removing the SN cell body. Short neurites have retracted, and there is a loss of several varicosities. Scale bar, $12.5 \mu \mathrm{m}$.

EPSP amplitude was reversible (Fig. 3). EPSP amplitudes were measured during a $48 \mathrm{hr}$ period after cutting the SN axon (Fig. $3 A-C)$. After $2 \mathrm{~d}$ in culture and before removing the $\mathrm{SN}$ cell body (Fig. $3 A$ ), average baseline EPSP amplitudes were not significantly different $(19.2 \pm 4.5 \mathrm{mV}$ for control, $17.2 \pm 2.8 \mathrm{mV}$ for cut axon, and $15.6 \pm 2.8 \mathrm{mV}$ for cut axon plus anisomycin groups, respectively). Treatment with anisomycin ( $n=8$ cultures) blocked the increase in EPSP amplitude during the first $24 \mathrm{hr}$ period. After washout of anisomycin, EPSP amplitudes increased during the second $24 \mathrm{hr}$ period (Fig. $3 D, E$ ). During the first $24 \mathrm{hr}$ period, EPSP amplitudes for control and cut axon groups $(n=8$ cultures each) increased significantly $(p<0.05)$ compared with initial baseline EPSP amplitudes (to $32.4 \pm 5.2$ and $28.0 \pm 3.7$ $\mathrm{mV}$, respectively). Treatment with anisomycin resulted in little change in the average EPSP amplitude to $16.2 \pm 3.6 \mathrm{mV}(p>$ 0.7). During the second $24 \mathrm{hr}$ period, the control and cut axon groups increased significantly compared with baseline EPSP amplitudes $(p<0.01)$ to $41.0 \pm 6.5$ and $35.6 \pm 4.4 \mathrm{mV}$, respectively. After washout of anisomycin, the average EPSP amplitude for the cut axon plus anisomycin group now increased significantly compared with baseline $(p<0.05)$ to $24.6 \pm 4.7 \mathrm{mV}$. The resumption of changes in synaptic efficacy after washout of anisomycin sug- gests that the translation of stable mRNAs already transported to $\mathrm{SN}$ neurites contribute to the formation of new functional connections.

\section{Changes in synaptic efficacy in the absence of L7 cell bodies require new protein synthesis}

We next examined whether SNs can form synapses with L7 in the absence of the L7 cell body. L7 cells were first plated alone (Fig. $4 A)$. The next morning (15-18 hr later), the cell body was removed and then an $\mathrm{SN}$ was plated close to the remaining neuritic processes of L7 (Fig. 4B). Control cultures were prepared in the same way without removal of the L7 cell body. EPSP amplitudes were measured $2 \mathrm{~d}$ later. There was no significant difference in the average EPSP amplitudes (Fig. 4C,D). The average EPSP amplitude for the control group was $18.4 \pm 1.7$ and $16.7 \pm 2.7 \mathrm{mV}$ for the cultures without the L7 cell body ( $n=10$ cultures each). These results suggest that synapse formation is initiated and proceeds in the absence of the L7 cell body.

Can synaptic connections form in the absence of both the presynaptic and postsynaptic cell bodies? We followed the same culture protocol as described in the paragraph above and removed the SN cell body $24 \mathrm{hr}$ after plating the $\mathrm{SN}$ with the L7 
A

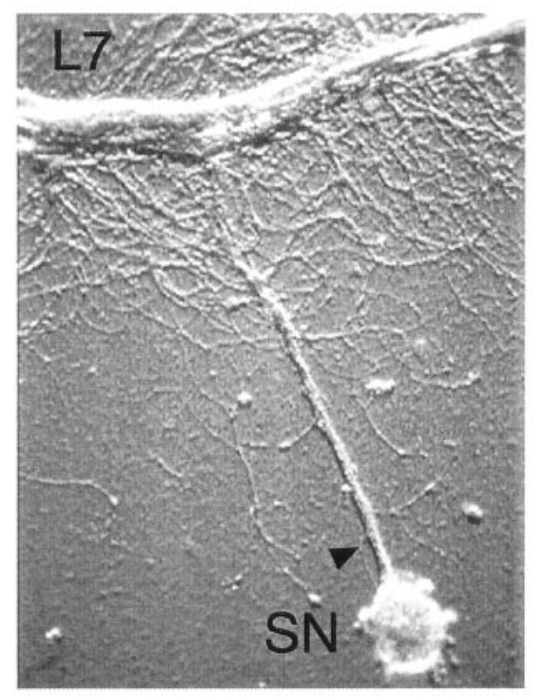

B

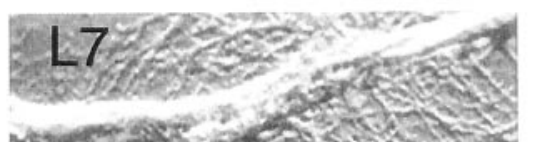

C

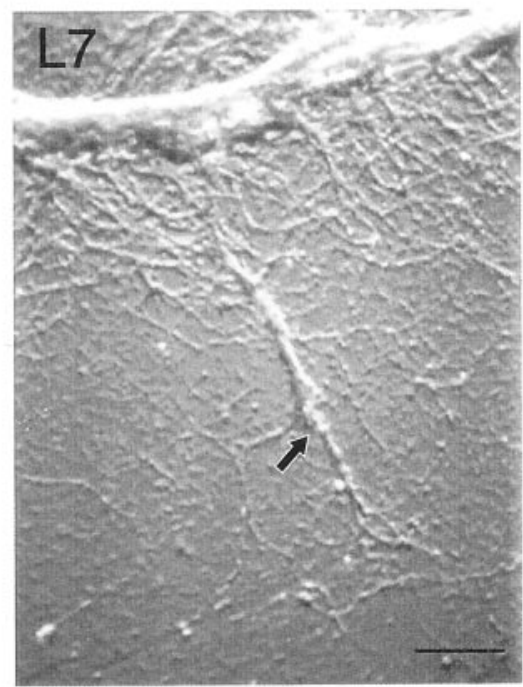

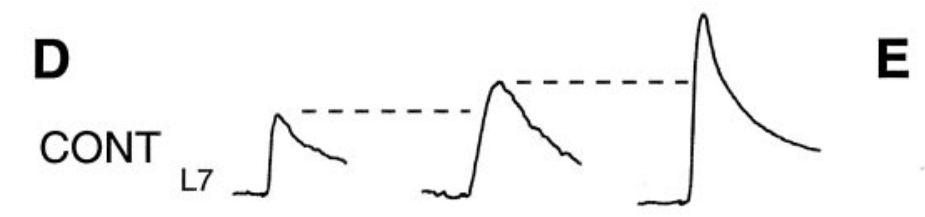

$\mathbf{E}$
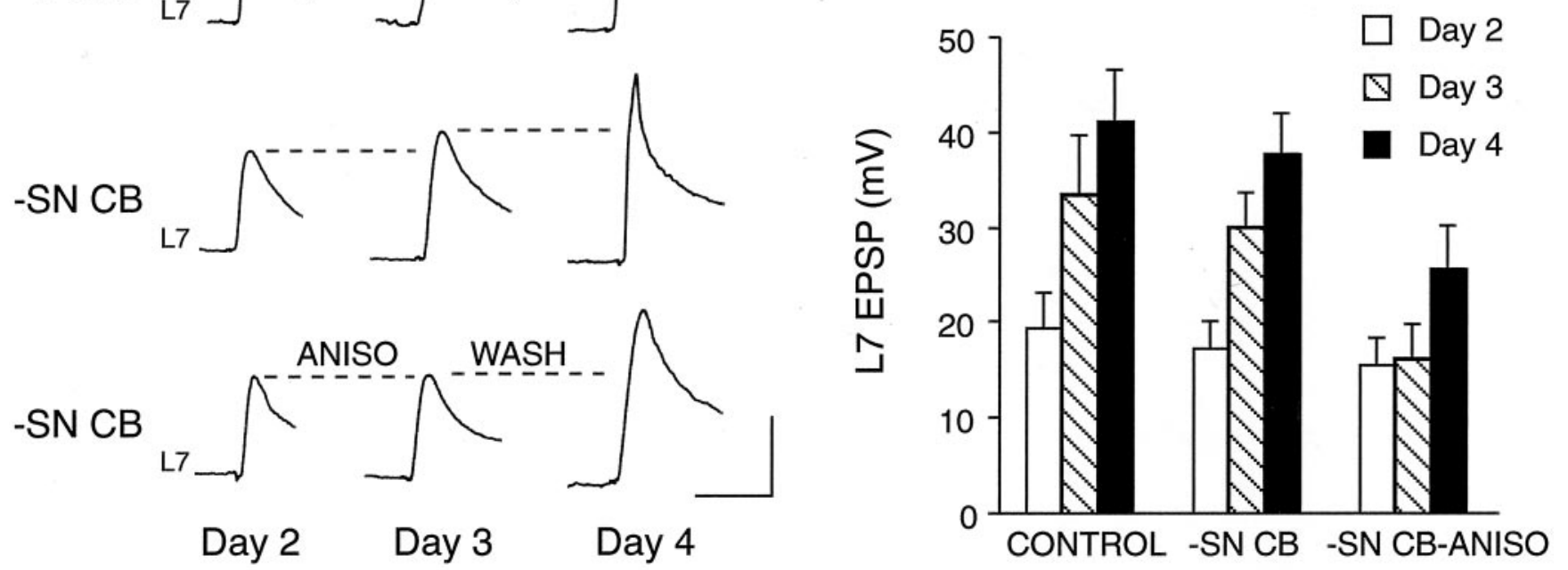

Figure 3. Anisomycin reversibly blocks increases in synaptic efficacy in the absence of the SN cell body. $A-C$, Photomicrographs of the same culture before $(A), 24 \mathrm{hr}(B)$, and $48 \mathrm{hr}(C)$ after cutting the $\mathrm{SN}$ axon at the arrowhead in $A$. Anisomycin was added 30-60 min after cutting the SN cell body and washed out $24 \mathrm{hr}$ later. After cutting the SN cell body, EPSPs were evoked in L7 by stimulating the axon stump (arrow in $B$ and $C$ ) with an extracellular electrode. Note a portion of the L7 axon at the top of each figure. Scale bar, $50 \mu \mathrm{m}$. $D$, Examples of EPSPs evoked in the same cultures before and after the various treatments. EPSP amplitudes increased at each time point (Day 3 and Day 4 ) in both the control cultures (CONT) and cultures without an SN cell body $(-S N C B)$. EPSP amplitudes increased in the remaining group only after washout of anisomycin $(A N I S O$ WASH; Day 4). Calibration: $15 \mathrm{mV}, 25 \mathrm{msec}$. E. Summary of the EPSP amplitudes (mean \pm SEM) before treatments (Day 2) and after treatments (Day 3) and washout (Day 4$)$. An ANOVA indicated a significant effect of treatment $(F=5.006 ; p<0.01)$. Note that EPSP amplitudes in the absence of SN cell body $(-S N C B)$ increase over time as the control group. Treatment with anisomycin blocks the increase in EPSP amplitude, which recovers with washout (see Results).

neurites (Fig. $5 A, B$ ). In one group of cultures, the preparations were then treated with anisomycin ( $n=8$ cultures). The other group of cultures served as control ( $n=8$ cultures). EPSP amplitudes were measured during the next $48 \mathrm{hr}$.

Increases in synaptic efficacy proceeds in the absence of all cell bodies. As described in Figure 4, SNs initiate synapse formation with L7 in the absence of the L7 cell body. The average EPSP amplitude $1 \mathrm{~d}$ after plating the $\mathrm{SN}$ was not significantly different for the two groups: $8.2 \pm 2.2 \mathrm{mV}$ for controls and $6.2 \pm 0.8 \mathrm{mV}$ for the cultures that will be treated with anisomycin at a later point. Removing the SN cell body as well does not disrupt the changes in synaptic efficacy measured $24 \mathrm{hr}$ later. After removing the SN cell bodies in the control culture, average EPSP amplitude increased to $19.8 \pm 4.1 \mathrm{mV}(p<0.05)$ compared with EPSP amplitude measured $24 \mathrm{hr}$ earlier. Adding anisomycin to cultures after removal of the SN cell body blocked the increase in EPSP 
A

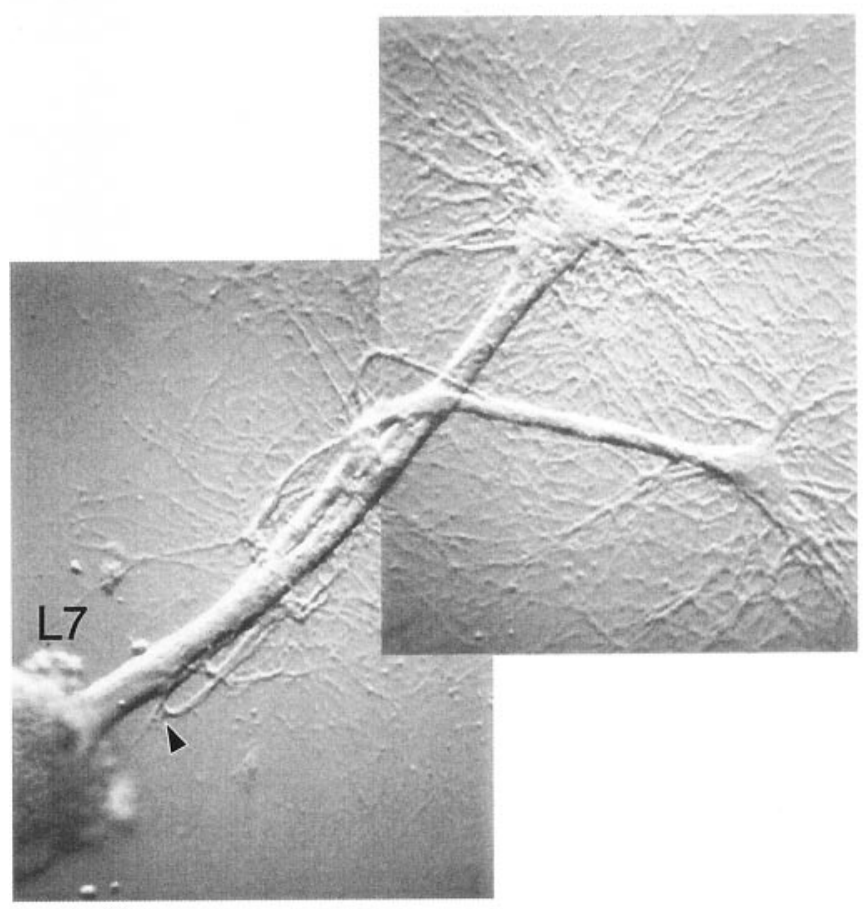

C
B

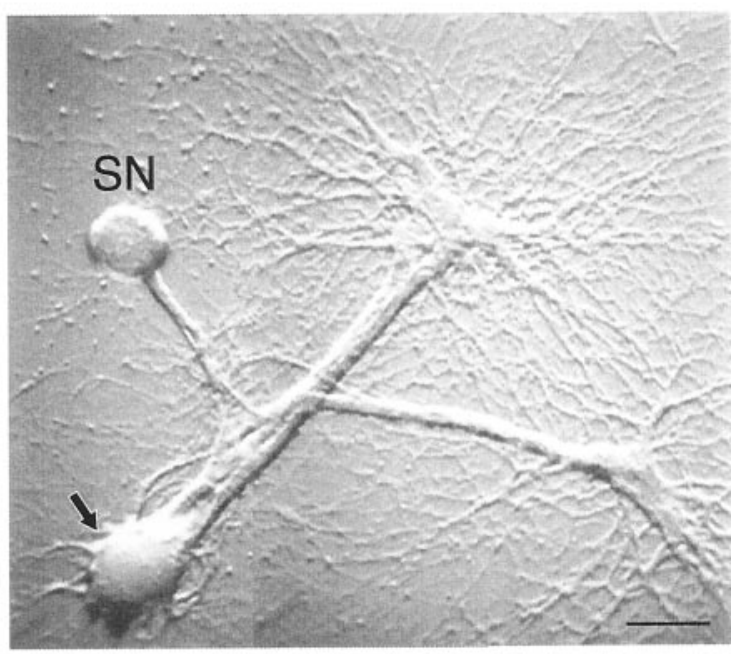

D

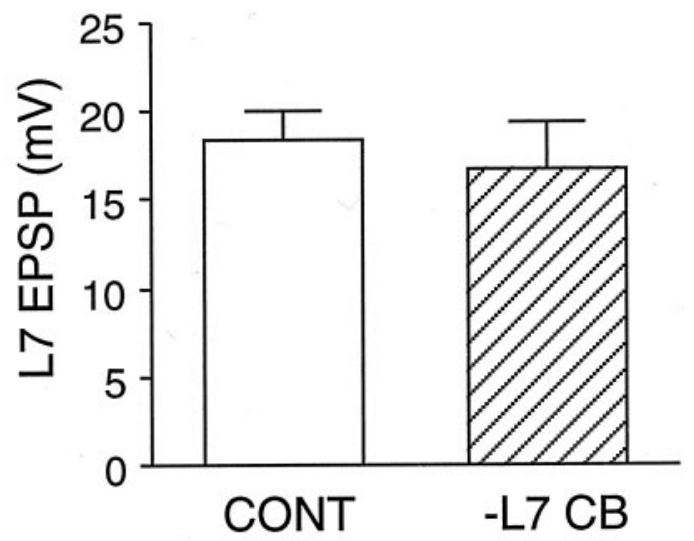

Figure 4. Synapse formation in the absence of L7 cell body. A, Photomicrograph of an L7 in culture alone for 18 hr before cutting the axon at the arrowhead. The cell body of L7 is located at the bottom left portion of the micrograph. B, Photomicrograph of the same culture 48 hr after cutting the L7 axon and then adding a single SN. EPSPs are evoked by stimulating the SN cell body and recording the response with an intracellular electrode in the new L7 stump (arrow). Scale bar, $50 \mu \mathrm{m}$. $C$, Examples of EPSP amplitudes $2 \mathrm{~d}$ after adding an SN to a culture without the L7 cell body ( $-L 7 C B$ ) and to a control culture prepared at the same time (CONT). Calibration: $15 \mathrm{mV}, 25 \mathrm{msec}$. $D$, Summary of the EPSP amplitudes recorded at 48 hr after adding an SN to L7 with (CONT) or without L7 cell body ( $-L 7 C B)$. EPSP amplitudes were not significantly different (see Results).

amplitudes. EPSP amplitudes in the anisomycin-treated cultures were virtually unchanged $(6.3 \pm 1.0 \mathrm{mV})$ compared with the average EPSP amplitude measured $24 \mathrm{hr}$ earlier. During the next $24 \mathrm{hr}$ period, the average EPSP amplitude in the control group increased further to $28.5 \pm 4.8 \mathrm{mV}$. With washout of anisomycin, average EPSP amplitudes now increased significantly $(p<0.05)$ to $18.0 \pm 1.6 \mathrm{mV}$. Thus, translation of stable mRNAs transported to the neurites of $\mathrm{SN}$ and/or L7 is required for the formation of new functional connections.

\section{DISCUSSION}

Our results suggest that protein synthesis at or near synaptic sites is required for the establishment of new synaptic contacts in the absence of cell bodies. In the absence of SN cell bodies, neurite extension and the formation of new SN varicosities in contact with the major processes of the postsynaptic neuron L7 accompany the increase in synaptic efficacy. These varicose structures contain the morphological features characteristic of transmitter release sites (Glanzman et al., 1989; Schacher et al., 1990; Hatada et al., 1999).
The protein synthesis inhibitor anisomycin blocks neuritic growth, the formation of new SN varicosities, and reversibly blocks the increase in synaptic efficacy. Thus, the translation of stable mRNAs exported to distal sites before removal of the cell bodies is critical for the formation of new synaptic connections.

The effects of anisomycin on the normal increases in synaptic efficacy and in the growth and varicosity formation by SN neurites suggest that protein synthesis in the neurites of the SN and L7 is critical for new synapse formation. Isolated neurites of Aplysia neurons synthesize proteins and synthesis at or near synaptic sites is required for the expression of synapse-specific long-term facilitation at established sensorimotor synapses by serotonin (Martin et al., 1997; Casadio et al., 1999; Sherff and Carew, 1999; unpublished observations). Local protein synthesis might increase transmitter release at preexisting synaptic contacts by modulating size and number of presynaptic active sites (Bailey and Chen, 1983, 1988) or the expression and insertion of transmitter receptors at postsynaptic sites (Zhu et al., 1997; Conrad et al., 1999; 

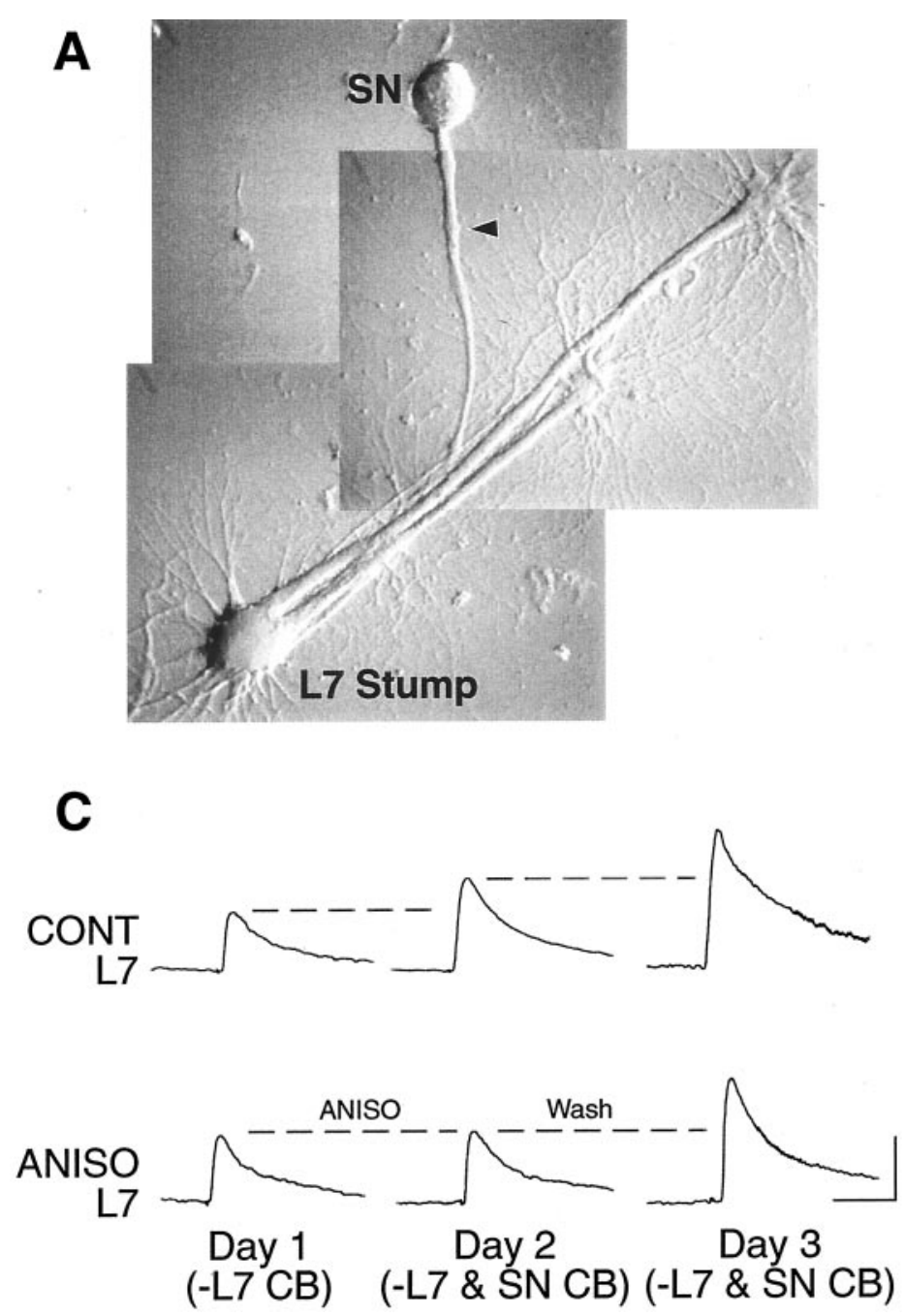

B

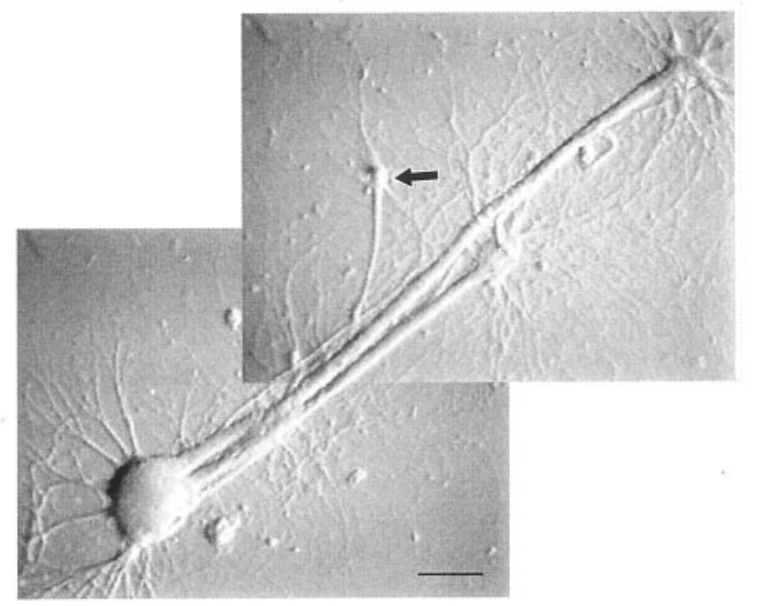

D

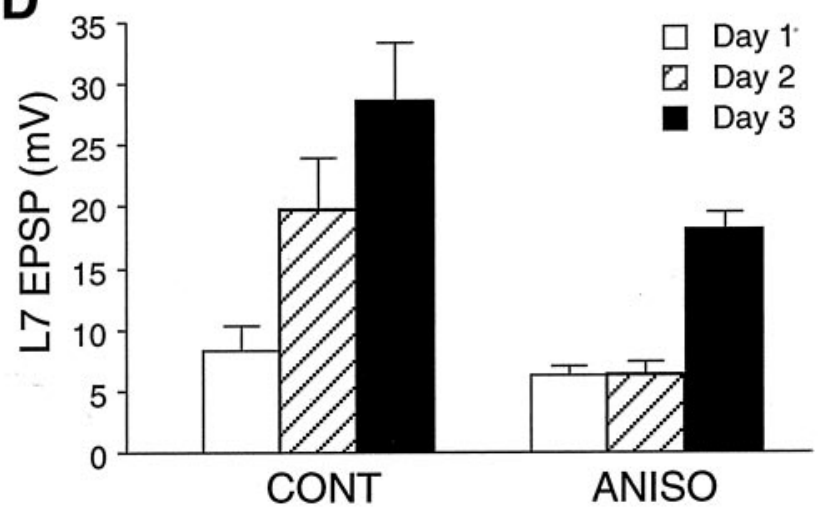

Figure 5. Protein synthesis-dependent synapse formation by SN neurites with L7 neurites in the absence of both cell bodies. $A$, Photomicrograph of $\mathrm{SN}-\mathrm{L} 7$ culture on day 1 without $\mathrm{L} 7$ cell body $(-L 7 C B)$ just after recording EPSP illustrated in $C(A N I S O)$. The SN was added to the culture after cutting the $\mathrm{L} 7$ cell body (Fig. 4). The SN axon was cut at the arrowhead. The culture was then incubated in medium containing anisomycin. $B$, Photomicrograph of the same culture $48 \mathrm{hr}$ later on day 3. The EPSP (see Day 2 and Day 3 in $C$ ) was produced in L7 by stimulating the SN axon stump (arrow). Scale bar, $50 \mu \mathrm{m}$. $C$, Examples of EPSPs produced in a control and an anisomycin-treated culture at each time point. SNs formed synapses with L7 in the absence of the L7 cell body (Day 1, $-L 7 C B$ ). EPSP amplitude increased in the absence of both the L7 and SN cell bodies (CONT, Day 2 and Day 3, $-L 7 \& S N$ $C B)$. The increase in efficacy is reversibly blocked by anisomycin (ANISO, Day 2 and Day 3). Calibration: $10 \mathrm{mV}, 25 \mathrm{msec}$. D, Summary of the changes in EPSP amplitudes (mean \pm SEM) in the control $(C O N T)$ and anisomycin-treated (ANISO) groups. An overall ANOVA indicated a significant difference between the two groups $(F=7.066 ; p<0.005)$. Individual comparisons indicated a significant change in EPSP amplitude on days 2 and 3 in the control cultures over the EPSP amplitude recorded on day 1 (baseline): anisomycin blocked an increase in EPSP amplitude over baseline, and EPSP amplitude increased significantly compared with baseline after washout of anisomycin (see Results).

Chitwood et al., 2001). A number of mRNAs involved with membrane cycling at terminals are transported to distal neurites of SN-L7 cocultures (our unpublished observations). Local translation of exported mRNAs in SN neurites that encode for other proteins such as actin and the neuropeptide sensorin A are likely to contribute to neuritic growth and the assembly of new functional synapses (Santarelli et al., 1996; Schacher et al., 1999, Hatada et al., 2000; Sun et al., 2001). For example, neurite extension and the formation of new $\mathrm{SN}$ varicosities both require actin polymerization at preexisting varicosities (Hatada et al., 2000). In addition, levels of exported mRNA encoding sensorin and expression of sensorin peptides in $\mathrm{SN}$ varicosities increase with synapse formation (Santarelli et al., 1996; Casadio et al., 1997; Schacher et al., 1999; Sun et al., 2001). Thus, formation of new synaptic contacts may involve the local synthesis in SNs of actin and other molecules needed for growth cone motility and extension, varicosity formation, and synaptic function.

One role of the proteins synthesized locally in the formation of new SN varicosities appears to involve growth cone extension, motility, and varicosity formation. New SN varicosities form primarily from growth cones (Hatada et al., 1999, 2000). The growth cones form en passant varicosities through a series of pauses in extension, formation of a nascent varicosity, and subsequent extension of a neurite tipped with a growth cone. Because anisomycin blocks extension by SN growth cones (Fig. 2), this effect of the inhibitor could prevent the subsequent increases in varicosity formation that appears to contribute to increases in synaptic efficacy during the first days of coculture (Zhu et al., 1994). Previous studies (Coulson and Klein, 1997) found that new synapses can form rapidly between the cell bodies of an $\mathrm{SN}$ and a 
target motor neuron (adult siphon motor cells from the left abdominal ganglion) in the presence of anisomycin. All components necessary for synapse formation by these Aplysia neurons are presynthesized in the cell bodies and require no new protein synthesis for synapse assembly. In contrast, synapse formation between neuronal cell bodies isolated from the adult ganglia of Lymnaea requires new protein synthesis (Feng et al., 1997). For new synaptic contacts to form via growth cones as reported here, new protein synthesis at or near synaptic sites may be required for both extension of presynaptic growth cone and varicosity formation.

The ability of synapses to form in either the absence of the L7 cell body or the absence of both cell bodies makes it likely that local protein synthesis in the neurites of L7 also contribute to the formation of new synaptic connections. The distal processes of L7 (when cultured alone) have significant levels of various mRNAs and other components necessary for protein synthesis (Schacher et al., 1999) (our unpublished observations). Recent studies, however, present conflicting data on the role of protein synthesis in the postsynaptic neuron in long-term synaptic plasticity of sensorimotor synapses. Intracellular injection of the membraneimpermeable protein synthesis inhibitor gelonin into the postsynaptic motor cell (L7) failed to block the expression of long-term facilitation produced by serotonin (Trudeau and Castellucci, 1995; Martin et al., 1997), but gelonin injections into pedal motor neurons succeeded in blocking some forms of long-term facilitation (Sherff and Carew, 2000). One possible explanation for the difference is the size of the motor cell. In the previous studies, the inhibitor was injected into the cell body of the large motor cell L7. Failure to block facilitation with injection into the cell body of L7 may result from insufficient levels of gelonin in both the cell body and distal sites. In the later studies, gelonin was injected into smaller motor cells in the pedal ganglion. Sufficient levels of the inhibitor may have blocked protein synthesis in both the cell body and distal processes, thereby blocking the expression of long-term facilitation. Direct intracellular injection of gelonin into the new axon stump of either the SN or L7 would test directly the cellspecific requirement for protein synthesis in neurites for the formation of new synapses.

The ability of SNs to initiate synapse formation with L7 in the absence of the L7 cell body and to establish new contacts without the SN cell body for several days indicates that all of the machinery necessary for assembling new functional active zones is present in the distal neurites. This includes the necessary components for translating stable mRNAs that have been transported from the cell bodies. Formation of new synapses by isolated neurites may also require the synthesis and rapid local insertion of functional NMDA-like receptors on the surface of L7 that are apposed to new $\mathrm{SN}$ varicosities and the subsequent insertion of functional AMPA-like receptors as synaptic efficacy increased (Conrad et al., 1999). Isolated invertebrate axons are capable of synthesizing functional transmitter receptors and inserting them into their membrane surface (Spencer et al., 2000).

Proteins synthesized in the cell bodies of SN and L7 that are critical for synaptic function and transported toward synaptic sites via axonal transport are likely to contribute to the formation of new synaptic connections (Nakata et al., 1998; Ahmari et al., 2000). When the cell bodies are removed, the relatively large axons of both the SN and L7 contain proteins that had been synthesized in the cell body and transported into the axons to be used at distal synaptic sites. These molecules along with the proteins synthesized locally combine and together permit the formation of new synapses. Future experiments will determine the identity of some of the proteins synthesized at distal sites and in the cell body that are required for the formation and maintenance of new synapses.

\section{REFERENCES}

Ahmari SE, Buchanan J, Smith SJ (2000) Assembly of presynaptic active zones from cytoplasmic transport packets. Nat Neurosci 3:445-451.

Bailey CH, Chen M (1983) Morphological basis of long-term habituation and sensitization. Science 220:91-93.

Bailey CH, Chen M (1988) Long-term memory in Aplysia modulates the total number of varicosities of single identified sensory neurons. Proc Natl Acad Sci USA 85:2373-2377.

Bank M, Schacher S (1992) Segregation of presynaptic inputs on an identified target neuron in vitro: structural remodeling visualized over time. J Neurosci 12:2960-2972.

Benbassat D, Spira ME (1994) The survival of transected axonal segments of cultured Aplysia neurons is prolonged by contact with intact nerve cells. Euro J Neurosci 6:1605-1614.

Bittner GD (1991) Long-term survival of anucleate axons and its implications for nerve regeneration. Trends Neurosci 14:188-193.

Casadio A, Martin KC, Bailey CH, Chen M, Zhu H, Kandel ER (1997) Molecular mechanisms underlying synapse-specific long-term facilitation of Aplysia sensory to motor synapses. Soc Neurosci Abstr 24:234.

Casadio A, Martin KC, Giustetto M, Zhu H, Chen M, Bartsch D, Bailey CH, Kandel ER (1999) A transient, neuron-wide form of crebmediated long-term facilitation can be stabilized at specific synapses by local protein synthesis. Cell 99:221-237.

Chitwood R, Li Q, Glanzman D (2001) Serotonin facilitates AMPAtype responses in isolated siphon motor neurons of Aplysia in culture. J Physiol (Lond) 534:501-510.

Conrad P, Wu F, Schacher S (1999) Changes in functional glutamate receptors on a postsynaptic neuron accompany formation and maturation of an identified synapse. J Neurobiol 39:237-248.

Coulson RL, Klein M (1997) Rapid development of synaptic connections and plasticity between sensory neurons and motor neurons of Aplysia in cell culture: implications for learning and regulation of synaptic strength. J Neurophysiol 77:2316-2327.

Crino PB, Eberwine J (1996) Molecular characterization of the dendritic growth cone: regulated mRNA transport and local protein synthesis. Neuron 17:1173-1187.

Feng ZP, Klumperman J, Lukowiak K, Syed NI (1997) In vitro synaptogenesis between the somata of identified Lymnaea neurons requires protein synthesis but not extrinsic growth factors or substrate adhesion molecules. J Neurosci 17:7839-7849.

Glanzman DL, Kandel ER, Schacher S (1989) Identified target motor neuron regulates neurite outgrowth and synapse formation of Aplysia sensory neurons in vitro. Neuron 3:441-450.

Hatada Y, Wu F, Silverman R, Schacher S, Goldberg DJ (1999) En passant synaptic varicosities form directly from growth cones by transient cessation of growth cone advance but not of actin-based motility. J Neurobiol 41:242-251.

Hatada Y, Wu F, Sun ZY, Schacher S, Goldberg DJ (2000) Presynaptic morphological changes associated with long-term synaptic facilitation are triggered by actin polymerization at pre-existing varicosities. J Neurosci 20:RC82(1-5).

Huber KM, Kayser MS, Bear MF (2000) Role for rapid dendritic protein synthesis in hippocampal mGluR-dependent long-term depression. Science 288:1254-1257.

Kang H, Schuman EM (1996) A requirement for local protein synthesis in neutrophin-induced hippocampal synaptic plasticity. Science 273:1402-1406.

Martin KC, Casadio A, Zhu H, Yaping E, Rose JC, Chen M, Bailey CH, Kandel ER (1997) Synapse-specific, long-term facilitation of Aplysia sensory to motor synapses: a function for local protein synthesis in memory storage. Cell 91:927-938.

Nakata T, Terada S, Hirokawa N (1998) Visualization of the dynamics of synaptic vesicle and plasma membrane proteins in living neurons. J Cell Biol 140:659-674.

Rayport SG, Schacher (1986) Synaptic plasticity in vitro: cell culture of identified Aplysia neurons mediating short-term habituation and sensitization. J Neurosci 6:759-763.

Santarelli L, Montarolo PG, Schacher S (1996) Neuropeptide localization in varicosities of Aplysia sensory neurons is regulated by target and neuromodulators evoking long-term synaptic plasticity. J Neurobiol 31:297-308

Schacher S, Glanzman DL, Barzilai A, Dash P, Grant SGN, Keller F, Mayford M, Kandel ER (1990) Long-term facilitation in Aplysia: persistent phosphorylation and structural changes. Cold Spring Harbor Symp Quant Biol 55:187-202. 
Schacher S, Wu F, Panyko JD, Sun ZY, Wang D (1999) Expression and branch-specific export of mRNA are regulated by synapse formation and interaction with specific postsynaptic targets. J Neurosci 19:63386347.

Sheetz AJ, Nairn AC, Constantine-Paton M (2000) NMDA receptormediated control of protein synthesis at developing synapses. Nat Neurosci 3:211-216.

Sherff CM, Carew TJ (1999) Coincident induction of long-term facilitation in Aplysia: cooperativity between cell bodies and remote synapses. Science 285:1911-1914.

Sherff CM, Carew TJ (2000) Induction of long-term facilitation at Aplysia sensorimotor synapses by coincident 5-HT exposure requires postsynaptic protein synthesis. Soc Neurosci Abstr 26:1523.

Spencer GE, Syed NI, van Kesteren E, Lukowiak K, Geraerts WP, van Minnen J (2000) Synthesis and functional integration of a neurotransmitter receptor in isolated invertebrate axons. J Neurobiol 44:72-81.

Steward O, Schuman EM (2001) Protein synthesis at synaptic sites on dendrites. Annu Rev Neurosci 24:299-325.

Steward O, Wallace CS, Lyford GL, Worley PF (1998) Synaptic activa- tion causes the mRNA for the IEG Arc to localized selectively near activated postsynaptic sites on dendrites. Neuron 21:741-751.

Sun ZY, Wu F, Schacher S (2001) Rapid bidirectional modulation of mRNA expression and export accompany long-term facilitation and depression of Aplysia synapses. J Neurobiol 46:41-47.

Trudeau LE, Castellucci VF (1995) Postsynaptic modifications in longterm facilitation: upregulation of excitatory amino acid receptors. J Neurosci 15:1275-1284.

Wu L, Wells D, Tay J, Mendis D, Abbott MA, Barnitt A, Quinlan E, Heynen A, Fallon JR, Richter JD (1998) CPEB-mediated cytoplasmic polyadenylation and the regulation of experience-dependent translation of alpha-CaMKII mRNA at synapses. Neuron 21:1129-1139.

Zhu H, Wu F, Schacher S (1994) Aplysia cell adhesion molecules and serotonin regulate sensory cell-motor cell interactions during early stages of synapse formation in vitro. J Neurosci 14:6886-6900.

Zhu H, Wu F, Schacher S (1997) Site-specific and sensory neurondependent increases in postsynaptic glutamate sensitivity accompany serotonin-induced long-term facilitation at Aplysia sensorimotor synapses. J Neurosci 17:4976-4986. 